\title{
Os conselhos gestores sob o crivo da política: balanços e perspectivas
}

\author{
Management councils screened by politics: \\ examinations and perspectives
}

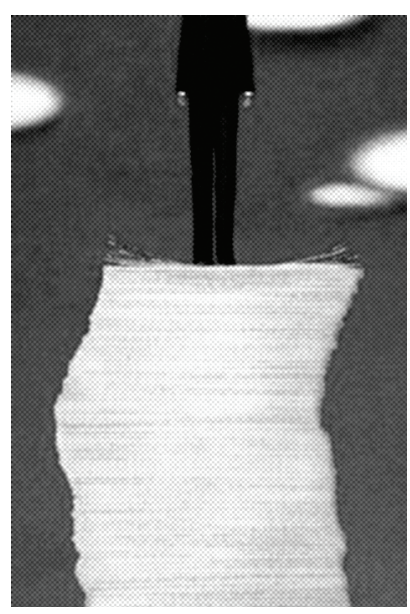

\author{
Carla Almeida* \\ Luciana Tatagiba**
}

Resumo: Neste trabalho, argumentamos que o cumprimento das expectativas democratizantes das quais os conselhos gestores são portadores depende da ampliação de sua audiência pública na sociedade e no Estado. Para ativar essas conexões, é necessário rever a rotina burocrática que hoje domina a agenda dos conselhos, conferindo maior centralidade ao exercício da política no seu funcionamento.

Palavras-chave: Conselhos gestores de políticas públicas. Democracia. Ação política. Participação.

\begin{abstract}
In this article, we assert that it is necessary to expand the management councils' public hearing in the society and in the State in order to accomplish the democratic expectations that they carry. To activate such connections, we must review the bureaucratic routine that dominates the councils' agenda nowadays to insert politics in the center of their functioning.
\end{abstract}

Keywords: Public policy management councils. Democracy. Political action. Participation.

* Mestre em Ciência Política (Unicamp) e doutora em Ciências Sociais (Unicamp). Professora da Universidade Estadual de Maringá Universidade Estadual de Maringá-PR, Brasil.E-mail:carlaalm@uol.com.br.

** Universidade Estadual de Campinas (Unicamp) — SP, Brasil.E-mail: lucianatatagiba@uol.com.br. 


\section{Introdução}

S conselhos de políticas públicas já atingiram a maioridade. Não
são mais "experiências" ou "apostas", termos frequentemente uti-
lizados para destacar a novidade que eles representaram desde que
emergiram nos debates constituintes como demanda da sociedade brasileira. Se os conselhos traduziram apostas, hoje refletem conquistas inegáveis do ponto de vista da construção de uma institucionalidade democrática entre nós.

Os conselhos são instâncias que se particularizam no interior do sistema decisório das políticas públicas pelo seu caráter plural e híbrido ${ }^{1}$ (Avritzer e Pereira, 2005), dado que são compostas por representantes estatais, representantes da sociedade civil e de prestadores de serviços públicos. Essa composição torna o processo decisório mais permeável aos diversos interesses implicados na elaboração e execução das políticas públicas, favorecendo decisões mais justas e legítimas.

Presentes na maioria dos municípios, articulados desde o nível federal, cobrindo uma ampla gama de temas, os conselhos figuram como parte importante do repertório de relação entre Estado e sociedade no Brasil contemporâneo. A tríade fundos, conferências e conselhos se espraiou pelo ordenamento político brasileiro, tornando-se a vértebra de sistemas institucionais em diversas áreas de políticas públicas. Os números evidenciam a magnitude dessas instâncias no arcabouço institucional brasileiro. O Munic/IBGE, de 2001, mostra, por exemplo, que mais de $90 \%$ dos municípios brasileiros registravam a presença de conselhos nas áreas da saúde, assistência e criança e adolescente. Pesquisa realizada por Tatagiba identificou um total de 541 conselhos em funcionamento na esfera estadual, com uma média de vinte conselhos por estado. A pesquisa mostra ainda que oito conselhos atingiram uma cobertura de $100 \%$ : alimen-

1. Sobre o uso da noção instituições híbridas para a análise da institucionalidade participativa, afirma Dolabela Pereira (2007, p. 342): "Podemos considerar 'órgãos híbridos' uma nova forma institucional que envolve a partilha de espaços de deliberação entre as representações estatais e as entidades da sociedade civil. [...] Essa nova forma de ação pública se caracteriza pela criação de espaços intermediários que têm como base a negociação e a parceria, ou, em outras palavras, uma partilha renovada de poderes institucionais que preconiza um novo agir político. [...] A adoção de políticas negociadas coloca em evidência o trabalho de 'mediação’ política e social necessária para a regulação dos conflitos”. 
tação escolar, assistência social, criança e adolescente, educação, saúde, meio ambiente, idoso e segurança alimentar. Outros conselhos também atingiram uma cobertura muito significativa, como no caso dos conselhos de cultura (presentes em $92 \%$ dos estados), deficiente (88\%), desenvolvimento agrário (88\%), antidrogas, mulher $(77 \%)$ e cidades $(70 \%)$. Esses números indicam a forte institucionalização dos conselhos no Brasil e sua diversificação temática (Tatagiba, 2011). É importante registrar ainda que as duas últimas gestões do governo federal destacam-se pelo forte ritmo de criação de conselhos num conjunto muito diversificado de áreas de políticas, com impactos também sobre os demais níveis da federação. Nos oito anos de governo Lula, foram criados dezesseis novos conselhos nacionais, número que corresponde a mais da metade dos então existentes no país (Mateos, 2011; Avritzer, 2009). Tendo em vista esse mapa da arquitetura da participação, podemos hoje falar num exército de conselheiros espalhados pelos quatro cantos do Brasil.

Os conselhos também se converteram, ao longo desses últimos vinte anos, em tema relevante dos debates sobre a democracia, contribuindo efetivamente para projetar a categoria sociedade civil no centro das formulações teóricas sobre as possibilidades das democracias contemporâneas. Assim, seguindo a trilha aberta pelos estudos seminais sobre o Orçamento Participativo, as análises sobre os conselhos alimentaram e foram alimentadas pelo debate teórico a respeito de modelos alternativos de democracia. ${ }^{2}$ Nele, o foco das atenções se deslocava das regras que organizam a competição pelo voto, das instituições políticas tradicionais e seus agentes específicos, e recaia nas modalidades de participação da sociedade civil e dos seus impactos na criação de novas instituições que teriam potencial para conferir maior legitimidade, justiça e eficácia às decisões políticas. O pressuposto central nesse debate, ainda que abrigue divergências e ênfases analíticas variadas, é o de que a legitimidade democrática nas sociedades contemporâneas, nas quais vigoram amplos dissensos e/ou fortes desigualdades, não pode ser satisfeita restritamente pela técnica de deci-

2. São referências importantes nesse debate os modelos de democracia surgidos no pós-1970, que apostaram, em comum, no ideário participativo, como o modelo de democracia participativa, baseado nas obras de Carole Pateman (1992 [1970]) e C. B. Macpherson (1978 [1977]), e o deliberativo, erigido, sobretudo, a partir das obras de Jürgen Habermas (1984 [1962] e 1997 [1992]). Como será mencionado mais à frente, o campo de estudo sobre os conselhos gestores e as demais inovações institucionais que abrigam atores da sociedade civil vem sendo marcado, recentemente, por propostas que enfatizam as relações entre participação e representação política. 
são aritmética das urnas. Ela requer uma institucionalidade capaz de amparar debates públicos que resultem em decisões pactuadas. Sob essa agenda formou-se uma geração de pesquisadores que se voltou para a compreensão dos dilemas e dos avanços da participação institucional, resultando em uma produção vigorosa e diversificada. ${ }^{3}$

Apesar dessas considerações que atestam o impacto teórico e institucional dos conselhos gestores, os estudos sobre o assunto mostram à exaustão que essa densa e variada arquitetura participativa tem esbarrado em limites que muitas vezes esvaziam ou restringem seus potenciais democratizantes. E aqui parece que estamos diante de um paradoxo: a vitalidade do modelo conselho/conferência/fundo e o seu peso no redesenho das políticas setoriais parece vir acompanhada de sua baixa capacidade para incidir nas correlações de força que conformam o jogo político em suas áreas específicas.

$\mathrm{O}$ argumento central deste artigo é que esse paradoxo - o baixo poder relativo dos conselhos vis-à-vis sua força como modelo de participação - está relacionado, entre outros fatores, à frágil ancoragem institucional e societária dessas instâncias. Ou seja, as disputas travadas no interior dos conselhos parecem ter dificuldades de extrapolar suas fronteiras e repercutir no ambiente politico-societal e político-institucional de forma mais ampla, o que limita seu poder na conformação das políticas setoriais, com impactos sensíveis sobre sua capacidade de democratizar as políticas públicas. Para reverter esse quadro, argumentamos também que é necessário rever as rotinas dos conselhos. Precisamos de mudanças na prática cotidiana dos conselhos que confiram maior centralidade ao exercício da política, em lugar da rotina burocrática da gestão. Estamos entendendo política como a ação que traz para a arena pública demandas por justiça que interpelam consensos e regras instituídas. Uma ação, portanto, que legitima e arma conflitos na sociedade visando, mediante negociações públicas, a redefinição dos termos sobre os quais se organizam o Estado e a sociedade. ${ }^{4}$ É preciso restituir o lugar desse tipo de ação na agenda dos conselhos

3. Recente levantamento realizado por Almeida e Tatagiba, nas bases da Capes e BBTD, identificou 340 teses e dissertações produzidas entre 2005 e 2009 abordando a temática dos conselhos. O levantamento indica, por exemplo, o espraiamento do interesse pelos conselhos em áreas de políticas públicas sem tradição participativa e mostra como essa temática tem se tornado objeto de atenção de estudos no campo da engenharia, agricultura, direito, bioética, contabilidade etc.

4. Essa concepção de política se inspira na análise de Feltran (2005), a qual, por sua vez, tem como fundamento as formulações presentes em Hannah Arendt e Jacques Rancière. 
para que eles possam funcionar como instâncias de democratização da gestão pública, e não restritamente como espaço de disputa entre interesses corporativos das comunidades de política, o que hoje parece ser a regra.

Esse olhar sobre os conselhos nos coloca, portanto, diante de outros parâmetros para realizar avaliações e balanços. Cada vez torna-se mais evidente que não é suficiente analisar os conselhos olhando apenas para suas dinâmicas internas. É preciso recuperar o ambiente mais amplo no qual eles se situam e sobre o qual buscam incidir. Assim, se a bibliografia sobre o assunto já nos possibilitou conhecer os problemas referentes à resistência dos governos a partilhar o poder de decisão, o papel dos projetos políticos na ampliação ou restrição das potencialidades democrática dessas instâncias, os conflitos entre governo e sociedade civil no seu interior, a necessidade de capacitação política etc., agora temos que ampliar o horizonte de problemas a considerar. Isso significa olhar as conexões que os conselhos estabelecem — ou não — com as demais instituições e públicos do seu entorno, como forma de apreender o seu poder relativo e sua capacidade de funcionar como instância de democratização da política pública.

Esses argumentos serão desenvolvidos em quatro itens. No primeiro, explicitamos os pressupostos normativos que orientam nossa análise. Nos dois seguintes, discutimos, respectivamente, a dupla face do entorno político dos conselhos, as quais julgamos urgente reconhecer e problematizar, a societal e a institucional. O último item é destinado ao argumento da revisão de rotinas dos conselhos, condição da qual depende, no nosso entendimento, as energias políticas necessárias para a ampliação de sua audiência pública na sociedade e no Estado, visando o exercício da política.

\section{Reconhecer avanços e calibrar as expectativas}

O primeiro pressuposto normativo que informa nosso olhar sobre os conselhos é o reconhecimento dos avanços que a criação dessa institucionalidade participativa representa enquanto resultado da aposta da luta por dentro do Estado como estratégia para construção de uma cidadania "desde baixo".

A disseminação das instituições participativas pelo país, como os conselhos, orçamentos participativos e fóruns, evidencia que apesar de todas as resistências e contramarchas, o projeto participativo se impôs como princípio na sociedade 
brasileira. Se esse fato não garante a priori sua continuidade e fortalecimento, e nem mesmo a direção que assumirá, não é pouco o que ele representa até aqui, já que determina patamares específicos para a luta política.

Embora a vontade política dos governos se constitua numa variável relevante da qual dependem a qualidade e os resultados do processo participativo, nenhum governo - a despeito de sua coloração partidária e inclinação democrática - pode hoje ignorar os conselhos nos processos de implementação da política. Mesmo que não tenham poder efetivo para decidir sobre a política pública, os conselhos têm poder de veto sobre as decisões do governo, podendo paralisar obras, vetar convênios, suspender o repasse de recursos etc.

Os conselhos gestores são também espaços nos quais se fomenta um importante aprendizado de convivência democrática, tanto para os atores da sociedade quanto do Estado. Tem exigido que o Estado dê publicidade as suas ações, apresente contas, exponha os critérios que balizam acordos; e, da sociedade civil, tem exigido que se qualifique para essa participação, o que amplia seu conhecimento dos processos que envolvem a gestão pública e possibilita a construção de novos referenciais capazes de equilibrar a defesa dos interesses privados e corporativos com o reconhecimento do caráter coletivo dos direitos implicados.

O segundo pressuposto que informa nossa abordagem dos conselhos gestores, e das demais instancias participativas, é o de que eles não estão destinados a cumprir com as apostas democratizantes que inspiraram sua criação, nem sua incapacidade intrínseca para cumpri-las pode ser afirmada unilateralmente. Seu grau de sucesso depende do resultado das disputas que se travam no seu interior e daquelas que se desenrolam no seu entorno. E estas não se realizam num vácuo, mas sob determinadas oportunidades e/ou constrangimentos político-institucionais. Desde os anos 1990, a partir de um conjunto de estudos de caso, temos visto que essa nova institucionalidade participativa tem ocupado um lugar ainda marginal nos processos decisórios que envolvem a definição das políticas em suas áreas específicas. ${ }^{5}$

Além disso, é preciso considerar que se os conselhos têm um papel a desempenhar na democratização da gestão pública. Eles possuem também limites

5. Os avanços das pesquisas apontam para a importância de algumas variáveis na análise dos impactos e resultados dos processos participativos, como o desenho institucional, o projeto político dos governos, o padrão associativo, a capacidade de investimento etc. 
que lhe são inerentes, como, por exemplo, a sua natureza setorial e fragmentada, sua forte dependência dos governos e uma tendência à burocratização dos processos participativos pela própria natureza de suas funções. Nesse sentido, como avalia de forma precisa Dagnino (2002, p. 296-297):

Atribuir indiscriminadamente aos espaços de participação o papel de agentes fundamentais na transformação do Estado e da sociedade, na eliminação da desigualdade e na instauração da cidadania, transformando as expectativas que estimularam a luta política que se travou pela sua constituição em parâmetros para sua avaliação, pode nos levar inexoravelmente à constatação do seu fracasso. Uma avaliação mais produtiva [...] deve partir do reconhecimento da complexidade desse processo e da diversidade dos contextos, envolvendo a multiplicidade de relações entre forças políticas onde ele se dá.

Compartilhando dessa visão, nosso terceiro pressuposto é o de que os conselhos gestores, assim como as demais instâncias participativas, são "peças" estratégicas no interior de um projeto de democratização do Estado e da sociedade, mas não podemos responsabilizá-los por todas as tarefas e esforços que exigem a construção daquele projeto.

Assim, reconhecer os avanços inerentes à consolidação da institucionalidade democrática armada pelos conselhos gestores e calibrar as expectativas endereçadas a ela é fundamental para irmos além da celebração de sua novidade histórica e passarmos a discutir as rotas e as dinâmicas que precisam ser alteradas tendo em vista o aprofundamento democrático. Estamos nos remetendo aqui às expectativas de que os conselhos sejam capazes de desafiar consensos dominantes em nome da afirmação dos direitos, não circunscrevendo suas ações às tarefas administrativas de gestão. Essa é uma avaliação que já está em curso, e seu avanço, julgamos, depende do reconhecimento e da discussão da dupla dimensão da ancoragem dos conselhos gestores: a político-societal e a político-institucional.

\section{A relação dos conselhos com a sociedade}

Até então elaboradas e analisadas como "novas formas de participação social", as inovações institucionais de composição híbrida como os conselhos gestores começaram mais recentemente a ser lidas por alguns analistas como 
expressão de uma "pluralização da representação política" (Gurza Lavalle, Castello e Houtzager, 2006), como expressão de novas formas de "autorização" que requerem, ao mesmo tempo, a participação e a representação política (Lüchmann, 2007) e como um tipo de "representação oficial da sociedade civil" com a qual o Estado tem, agora, que lidar (Avritzer, 2007). Embora não faça parte do propósito deste texto analisar as ricas implicações teóricas embutidas nessas leituras, ${ }^{6}$ julgamos fundamental abordar alguns dos problemas que a partir delas se tornaram obrigatórios no debate sobre os conselhos gestores e que dizem respeito, fundamentalmente, à sua ancoragem societal.

Ao chamarem a atenção para o fato de que nessas instâncias as organizações da sociedade civil protagonizam uma modalidade específica de representação, aquelas leituras reforçaram a necessidade de considerar a heterogeneidade de interesses que pode ser canalizada por essa via ${ }^{7}$ e, como consequência, reforçaram a importância de desnaturalizar a legitimidade de seus atores em centros decisórios de políticas públicas, como os conselhos. Pela desnaturalização dessa legitimidade entendemos o reconhecimento de que os atores da sociedade civil não são portadores de uma racionalidade imparcial como se encarnassem, em si, o "bem comum" ou o "interesse público". Eles são, ao contrário, portadores de concepções "situadas" e "parciais" do que deve ser o "bem comum", na maior parte do tempo, conflitantes e até mesmo antagônicas entre si.

6. Essas novas leituras sobre as inovações institucionais expressam um movimento teórico de maior escopo que vem ganhando projeção nos debates recentes sobre as democracias contemporâneas. Ele aponta os limites das abordagens que antagonizam participação e representação política e sua inadequação para a compreensão, seja do funcionamento das instituições tradicionais de representação (Urbinatti, 2006; Young, 2000 e 2006), seja dos arranjos institucionais que incluem atores da sociedade civil nos centros decisórios de políticas públicas (Gurza Lavalle; Insuza Vera, 2010; Peruzzotti e Selee, 2009). Algumas dessas abordagens, inclusive, preferem não qualificar as instâncias híbridas das quais estamos tratando neste texto como participativas, já que essa denominação obscureceria as novas modalidades de representação política que elas colocam, efetivamente, em funcionamento. Embora reconheçamos a pertinência dos motivos que amparam essa opção, consideramos que a referência à participação traduz de maneira mais forte aquilo que é o distintivo dessas instâncias no interior do sistema institucional brasileiro: a própria Constituição, via participação em organizações da sociedade civil, de novos atores nos processos decisórios. Assim, mantemos aqui a qualificação instâncias participativas como maneira de expressar o reconhecimento de que é a partir de uma modalidade específica de participação que se erigem as modalidades representativas que são características dos arranjos como os conselhos gestores.

7. Como exemplos de estudos que não apenas chamaram a atenção para a heterogeneidade constitutiva da sociedade civil, mas a colocaram no centro de suas análises sobre as inovações institucionais criadas pós1988, consultar, entre outros, as obras de Dagnino (2002) e Dagnino, Olvera e Panfichi (2006). 
Assim, se a consideração dos diversificados e conflitantes interesses que convivem no interior da sociedade civil não autoriza abordar seus agentes específicos como portadores, a priori, do interesse público, e se não há, portanto, uma coincidência automática entre os interesses que aqueles agentes defendem e o interesse de toda a sociedade civil, nem de toda a sociedade, é pertinente e absolutamente necessária, como condição de fortalecimento dos conselhos gestores, a preocupação com sua ancoragem social, desde onde pode se construir sua legitimidade.

Considerando essa preocupação, a garantia da legitimidade das organizações da sociedade civil que têm assento nos conselhos gestores, e a própria legitimidade dessa instância diante da sociedade, está intimamente associada a sua capacidade de obter uma audiência mais ampliada que vá além dos atores diretamente envolvidos com a produção da política. Isso é ainda mais urgente quando levamos em conta as implicações do caráter híbrido dos conselhos, característica que os particularizam enquanto vetores de encaminhamento de demandas sociais ao sistema político e enquanto instâncias de tomada de decisões governamentais. Afinal, nos conselhos, os atores sociais que carreiam as demandas para dentro do Estado o fazem também em nome dos interesses das organizações que eles representam. O que deve ser ressaltado aqui é que são essas mesmas organizações que processarão aquelas demandas em termos de decisões de políticas públicas.

Ou seja, estamos chamando a atenção para o fato de que as responsabilidades institucionais conferidas aos conselhos gestores no âmbito das políticas implicam uma justaposição de competências para seus atores: eles encaminham e ao mesmo tempo deliberam sobre demandas sociais; exercem o controle social e são objetos desse mesmo controle; são responsáveis pelo controle e, muitas vezes, pela própria execução das políticas. Essa justaposição de competências - e as tensões que carrega - se mostra ainda mais dramática nos casos daquelas organizações que representam, no conselho, prestadores de serviço. É preciso reconhecer as tensões que tal justaposição implica para que elas não se expressem em privilégios e reproduzam privatismos. Afinal, como declarou um conselheiro da assistência social, citado em estudo de Almeida (2009) sobre Maringá (PR): “é dificil ser neutro quando se trata de avaliar a sua própria entidade". Esse depoimento explicita a necessidade e ao mesmo tempo a dificuldade de construir as medidas que permitam que as negociações dos interesses particulares presentes no conselho possam se orientar por critérios públicos e transparentes. 
Podemos dizer então que no caráter híbrido dos conselhos gestores repousa tanto o seu potencial para democratizar as decisões políticas quanto os riscos de que essas decisões atendam meramente interesses específicos. Os conselhos foram criados para favorecer a entrada e a publicização de tais interesses nos processos decisórios, para promover a influência dos mais variados interesses nas instâncias que deliberam sobre assuntos coletivos. Entretanto, para cumprir com as expectativas que inspiraram sua criação, a justaposição de competências antes mencionada não pode resultar em decisões que restritamente acomodem interesses particulares. É nesse sentido que estamos chamando a atenção para a necessidade e os conselhos gestores obterem uma audiência pública e social maior, como forma de contrabalançar o peso de certas categorias e de certos interesses no seu interior. ${ }^{8}$

Muitos estudos de caso comprovam que os conselhos são pouco conhecidos para além do universo das organizações da sociedade civil diretamente envolvidas com a temática e ainda apresentam muitas fragilidades quanto aos mecanismos legais de prestação de contas e divulgação mais ampla das decisões tomadas no seu interior (Vidal, 2011; Santos Júnior, Azevedo e Ribeiro, 2004). Outros estudos concluem ainda que há uma baixa conexão entre conselhos e movimentos populares, o que demonstraria uma descontinuidade entre a mobilização popular da década de 1980 e a atuação nessas instâncias (Tótora e Chaia, 2004).

Por isso, é preciso criatividade para forjar novas formas de comunicação com a esfera pública, que traduzam os temas dos conselhos visando criar audiências ampliadas para a agenda dos direitos. Ao apostar na constituição dessa audiência mais ampliada, essas iniciativas podem articular de forma interessante a luta institucional com a mobilização societária, constituindo um círculo virtuoso promissor. Essa audiência é fundamental para que se construam critérios de avaliação com respaldo social para a atuação das organizações que têm representação no conselho e que, muitas vezes, prestam serviços públicos.

Por certo, há várias experiências nesse sentido pelo Brasil afora. É preciso conhecê-las e divulgá-las não para forjar modelos a serem replicados, mas para fecundar a imaginação. As conferências já cumprem um papel importante

8. Livro organizado por Soraya Côrtes (2009) traz uma discussão muito interessante em torno desse ponto ao destacar o papel protagônico assumido pelos profissionais e trabalhadores da saúde no Conselho Nacional de Saúde e suas consequências sobre as dinâmicas internas do conselho e o seu papel na rede da política pública. 
nessa direção, mas elas não são suficientes para responder ao conjunto das exigências postas para a ampliação da audiência pública dos conselhos. Para além de prestar contas para a sociedade de forma mais ampla, aquela audiência requer instâncias que amparem processos públicos de formação das vontades políticas e de agregação de interesses, elementos fundamentais da prática representativa.

Requer, ainda, instâncias nas quais a própria definição dessa representação seja objeto de uma discussão mais ampla. E aqui tocamos numa das questões mais espinhosas que envolvem o debate sobre a representação nos conselhos gestores porque, afinal, quem tem direito de pleitear esse estatuto e por quais razões? Concordamos com Dowbor, Houtzager e Serafim (2008), de que é absolutamente necessário que os atores da sociedade civil se preocupem com essas perguntas antes que outros ocupem o lugar legítimo para respondê-las. ${ }^{9}$ Até porque determinadas exigências hoje em vigor para algumas áreas de políticas acabam muitas vezes bloqueando o acesso de certas organizações da sociedade civil aos conselhos gestores. Como afirmou Moroni (2011, p. 3):

Os critérios usados para se participar são excludentes, tais como, por exemplo, pertencer a grupos institucionalizados. Isso deixa muita gente de fora. O desafio é como pensar um sistema de participação popular que abarque todas as formas organizativas da sociedade e não apenas os institucionalizados.

De outro lado, consideramos absolutamente fundamental que a construção dessas instâncias públicas seja acompanhada de iniciativas que fomentem a apropriação do conselho pela sociedade. Inúmeros estudos de caso revelam que os conselhos podem se transformar em mais um dos nichos secretos do Estado ao não permitirem acesso público às suas reuniões ou criarem dificuldades para a consulta de suas atas. Não tem sentido a discussão que estamos fazendo aqui sobre a necessidade de apostar numa audiência pública maior para os conselhos na sociedade se seus próprios procedimentos rotineiros são obstáculos para isso acontecer. Consideramos que essa exigência deve compor a agenda de discussão

9. Nesse sentido, vale mencionar que a pesquisa de Abranches e Azevedo (2004) sobre conselhos municipais da Região Metropolitana de Belo Horizonte identificou que a escolha de $30 \%$ dos representantes da sociedade civil investigados havia sido influenciada pelo poder público, e apenas uma minoria das entidades com assento nos conselhos havia definido os conselheiros por meio de instâncias mais públicas, como conferências municipais ou fóruns sociais. 
das conferências, instâncias superiores de onde partem as diretrizes para a atuação dos conselhos nas mais variadas esferas de governo. Isso porque o atendimento dessa exigência, que é bastante preliminar para a democratização das instâncias decisórias mas que tem se mostrado de difícil concretização em muitos casos, não pode depender das correlações de forças momentâneas que dão a direção para os conselhos gestores nos diversos contextos.

O conjunto dos fatores apresentados aqui aponta para a necessidade de fortalecer a ancoragem societal dos conselhos, o que requer não apenas uma aposta de energias nas instancias já existentes de comunicação entre conselhos — sociedade civil — sociedade, mas também a criação de novos procedimentos e espaços que conectem seus agentes. Além do que, requer que os próprios conselhos sejam apropriados pela sociedade. Em outras palavras e nos inspirando nas afirmações de Young (2006), a legitimidade e a qualidade da representação exercida pelos atores sociais nos conselhos e o fortalecimento dessa instância junto à sociedade requerem a fomentação da participação dos cidadãos e da sociedade civil. Desse modo, se aprendemos que os conselhos gestores expressam novas modalidades de representação política, agora concluímos que essas modalidades de representação não apenas estão associadas à participação, mas dela depende suas próprias bases de legitimidade.

\section{A inserção dos conselhos gestores na rede estatal de produção das políticas públicas}

Um dos principais pontos da luta política envolvida com a criação e o funcionamento dos conselhos diz respeito à garantia do seu papel deliberativo no interior do sistema das políticas públicas. Compreende-se isso se notamos que o adjetivo "deliberativo" abriga as expectativas de que tais instâncias invertam prioridades, distribuam de forma justa os recursos públicos e promovam direitos, fazendo assim a diferença enquanto instância decisória. Mas, ao mesmo tempo, é também no diagnóstico da sua incapacidade de exercer o papel deliberativo que boa parte dos apontamentos críticos e das frustrações políticas repousa.

Por isso mesmo, julgamos necessário interrogar os termos que devem orientar a luta pela garantia do caráter deliberativo dos conselhos. Para isso, 
não podemos prescindir de uma discussão mais profunda sobre o seu papel e sobre as suas condições de atuação na rede estatal de controle e de deliberação das políticas públicas. ${ }^{10}$ Isso exige, portanto, reconhecer o ambiente institucional mais amplo nos quais eles estão inseridos.

Os conselhos estão obrigados legalmente a atender exigências específicas que partem de outras instâncias que têm alguma jurisdição sobre a área de política pública na qual atuam, como, por exemplo, dos tribunais de contas, dos ministérios públicos, dos legislativos e de órgãos executivos (Ministérios e secretarias municipais e estaduais). Trata-se, na verdade, de instâncias conectadas legalmente e que possuem obrigações legais recíprocas. Estas se expressam em legislações e resoluções que normatizam desde os princípios organizadores de uma área de política até suas fontes de recursos, seus instrumentos de gestão, mecanismos e instâncias de execução e fiscalização etc. Por exemplo, o documento que normatizou a gestão do Suas (Sistema Único de Assistência Social) assim explicitou a rede institucional implicada no controle estatal dessa política, bem como os mecanismos e instrumentos nos quais esse controle deve ser basear:

A fiscalização dos recursos financeiros relativos ao Suas é de competência dos gestores federal, do Distrito Federal, estadual e municipal, dos órgãos de controle interno do governo federal, do Tribunal de Contas da União (TCU), Tribunais de Contas dos Estados (TCE), Tribunal de Contas do Distrito Federal (TCDF), Tribunais de Contas dos Municípios, quando houver, e demais órgãos do Legislativo, bem como dos Conselhos de Assistência Social, resguardadas as responsabilidades e autonomia de cada esfera de governo no processo de gestão descentralizada, sendo efetuada por mecanismos como auditorias, inspeções, análises dos processos que originarem os Planos Estaduais de Assistência Social, o Plano de Assistência Social do Distrito Federal ou os Planos Municipais de Assistência Social e prestações de contas utilizados como base para o relatório de gestão, bem como outros mecanismos definidos e aprovados oportunamente pelas instâncias competentes. (Ministério do Desenvolvimento Social, NOB-Suas, 2005, p. 55; grifos nossos)

Como se vê, os conselhos figuram como uma entre várias instâncias que têm, em alguma medida, a responsabilidade de exercer o controle interno do Estado sobre as políticas públicas. Diante dessa complexa teia institucional, tecida por obrigações legais, em que medida podemos esperar que os conselhos

10. Os argumentos apresentados nesse item estão baseados em Almeida (2009). 
assumam sua função deliberativa? Até porque, muitas vezes, o exercício dessa função entra em conflito direto com alguns dispositivos institucionais. Vejamos, por exemplo, o caso das emendas parlamentares especificas na área da assistência. Por essa modalidade de transferência de recursos, os parlamentares podem destinar recursos para determinadas entidades da rede de assistência social. Nesse caso, embora os conselhos tenham que avalizar essa transferência, ela pode se chocar diretamente com seu planejamento de distribuição de recursos e com as prioridades da política que essa instância definiu para sua realidade. $\mathrm{O}$ trabalho tão árduo enfrentando pelos conselheiros dessa área para definir critérios públicos e justos de distribuição de recursos, nessas condições, é atropelado pela prerrogativa parlamentar de definir uma entidade em especial como beneficiária das emendas. ${ }^{11}$ Essas emendas, portanto, constrangem a competência deliberativa atribuída aos conselhos para definir a distribuição de recursos nas suas esferas de governo correspondentes, deixando descontentes tanto a representação governamental como a da sociedade civil. Isso porque, mesmo nesses casos, o executivo tem que oferecer contrapartidas para que os recursos sejam recebidos pela entidade selecionada pelo parlamentar, mas para implementação de projetos que, muitas vezes, não foram definidos com sua participação. De outro lado, as emendas específicas, beneficiando determinadas entidades, criam ou reforçam desigualdades e hierarquias no interior das que representam a sociedade civil.

Por isso mesmo, o documento que definiu as diretrizes para a Política Nacional de Assistência Social no país não apenas apresentou seus elementos constitutivos como também indicou, claramente, que sua implementação estava em confronto com determinadas modalidades e dispositivos então vigentes de financiamento para essa política:

Outro elemento importante nessa análise da forma tradicional de financiamento da política de assistência social são as emendas parlamentares que financiam ações definidas em âmbito federal, de forma desarticulada do conjunto das instâncias do sistema descentralizado e participativo. Isso se dá, muitas vezes, pela não articulação

11. Sobre esse assunto, remetemos ao depoimento de uma conselheira da assistência social da cidade São Paulo, citado em estudo de Teixeira e Tatagiba (2007b): "Era um jogo de interesses muito grande: as organizações sociais que queriam receber o recurso da emenda parlamentar; o parlamentar que tinha o interesse eleitoral de que a organização recebesse o recurso; o gestor que não queria ficar mal nem com o parlamentar e nem com a organização; e o Conselho no meio dessa discussão". 
entre os poderes Legislativo e Executivo no debate acerca da Política Nacional de Assistência Social, o que se pretende alterar com a atual proposta. (Ministério do Desenvolvimento Social, PNSA, 2004, p. 43; grifos nossos)

Essa situação é reveladora do quanto o sistema interno estatal de controle e deliberação das políticas públicas não se rege por uma lógica harmônica, coesa e equilibrada, na qual as instâncias têm papéis diferentes e complementares. O fluxo das regulações e das deliberações do qual resultam as políticas públicas é constituído por dispositivos e modalidades que se superpõem e muitas vezes estão em conflito. Somando-se a isso, as posições hierárquicas que as instâncias ocupam no interior de um sistema não são fixas. Elas podem se mover mediante confrontos que tenham capacidades para produzir impactos institucionais e novos arranjos internos, como mostra o que a própria PNAS (Política Nacional de Assistência Social) deseja para viabilizar a concretização de suas diretrizes.

Levando o conjunto desses fatores em conta, a função deliberativa dos conselhos não pode ser confundida com sua autonomia político-institucional. Essa confusão nubla o reconhecimento da especificidade do tipo de luta política que pode ser travada via conselhos. Eles são estratégias de lutas por dentro do Estado, visando sua democratização, e não sobre ou paralelamente a essa instituição. Reconhecer essa especificidade é fundamental para superar as avaliações marcadas por frustrações decorrentes de expectativas que os conselhos não podem cumprir, o que gera imobilismo político.

Para superar essas frustrações e construir uma agenda de ação política mais adequada, podemos compreender os conselhos como instâncias pelas quais passam os variados e muitas vezes conflitantes fluxos de deliberação e de regulação que emanam de pontos distintos do aparelho do Estado e que incidem na sua área de política correspondente. Podemos considerar também que os dispositivos e as modalidades reguladoras e deliberativas institucionais variadas funcionam como transmissores dos compromissos estabelecidos entre sujeitos distintos - estatais e não estatais - envolvidos no universo de produção e execução das políticas. Retomando o caso em tela, as emendas parlamentares específicas expressam os compromissos mútuos estabelecidos entre parlamentares e entidades de assistência social.

Sugerimos aqui que o exercício do caráter deliberativo dos conselhos está diretamente associado à sua capacidade de superar a posição de mero espaço de 
passagem daqueles fluxos para se constituir num espaço legítimo e efetivo de sua interpelação segundo as exigências públicas da justiça e dos direitos. Restritos a meros espaços de passagem, suas deliberações apenas cumprem formalidades e avalizam decisões tomadas por outras instâncias. Assim os conselhos não causam nenhum ruído nos circuitos decisórios estatais. Ao contrário, o exercício efetivo do seu caráter deliberativo impõe que os conselhos funcionem como uma espécie de "nó" dos fluxos deliberativos e reguladores, ou seja, como espaços nos quais esses fluxos e os interesses que os subjazem devem se ajustar às demandas por justiça. A inscrição do caráter deliberativo dos conselhos em legislação fornece o suporte institucional para que eles ocupem essa posição, enquanto o caráter híbrido de sua composição lhe fornece o suporte político. Portanto, o principal desafio institucional dos conselhos é buscar sua legitimidade política no interior do Estado de modo que não seja possível para os demais representantes legalmente instituídos desconsiderar suas exigências, por mais que elas estejam em confronto, a princípio, com determinados dispositivos e modalidades reguladoras e deliberativas. Até porque, como já mencionamos, as posições das instâncias estatais no interior do sistema das políticas públicas não são fixas; elas se movem e se acomodam mediante confrontos e acomodações de interesses no interior do Estado. Assim, se as instâncias participativas adquiriram uma magnitude significativa no interior daqueles sistemas no Brasil, isso não significa que outras instâncias não possam disputar o lugar legítimo de cumprir funções e competências previamente designadas aos conselhos. Isso fica evidente no estudo de Côrtes et al. (2009, p. 63) sobre a área da saúde. Conforme os autores,

tanto os conselheiros entrevistados [...] quanto a literatura [...] salientam que as comissões intergestores criadas no início da década de 1990 [...] passaram a ser as principais arenas institucionais de tomada de decisões sobre a política de Saúde no país. Isto teria afetado negativamente a capacidade do Conselho Nacional de saúde de se consolidar como um fórum central de decisão sobre a política de saúde nacional.

Desse modo, os autores concluem que as Comissões Intergestores Tripartite e Bipartites de pactuação federativa na área da saúde passaram a funcionar como as principais instâncias de tomada de decisões sobre o financiamento, a estruturação e o funcionamento do sistema de saúde, "reduzindo o interesse de gestores e prestadores de serviço de controlar as atividades do conselho, visto a partir de então como fórum decisório secundário" (Idem, p. 67-68). Esse caso 
é bastante significativo para o argumento que estamos defendendo aqui: a luta política não deve ser travada apenas no interior dos conselhos, mas pelo fortalecimento dos conselhos no interior do Estado. O estudo em questão permite concluir que foi determinante para a fragilização do poder decisório do Conselho Nacional de Saúde a falta dessa percepção: "os atores sociais que participavam do Conselho [...] optaram por uma estratégia que visava ampliar o seu controle sobre o fórum, e não a fortalecê-lo como espaço decisório na arena da política de saúde" (Côrtes et al. 2009, p. 66).

Assim, é preciso insistir que a função deliberativa dos conselhos não se expressa na sua suposta autonomia diante das outras instâncias estatais. Sua função deliberativa começa pelo reconhecimento dessas instâncias e pela disposição de travar uma luta no interior do Estado para se constituir, diante delas, num interpelador legítimo das normas vigentes quando assim exigem as demandas sociais por justiça. É essa interpelação que estamos entendendo aqui por política, e é ela que pode gerar as mudanças almejadas para as políticas públicas. Na ausência de disposição para atuar dessa forma, podemos ver dissolvidas a própria justificativa da existência dos conselhos. E essa é uma percepção que já está presente nos debates sobre o tema, como mostra a afirmação de José Antonio Moroni, do Instituto de Estudos Socioeconômicos (Inesc), ao notar que as lutas sociais são combustíveis dos quais depende uma atuação institucional com capacidade de provocar tensões:

[...] esses espaços institucionalizados precisam ser tensionados pelas lutas sociais, inclusive os espaços participativos. Não ocorrendo isso, acontece o que vemos hoje, esses espaços deixam de ser espaços de disputas políticas e passam a ser espaços burocráticos ou de ocupação de posição. Isso é a morte dos processos participativos. (Moroni, 2011)

\section{Rever rotinas para dinamizar a agenda política}

Se nos itens anteriores sugerimos que os conselhos estão voltados sobre si mesmos, desconectados ou fracamente conectados com seu ambiente institucional e societário mais amplo, nesse buscamos sustentar a ideia de que uma das formas de superar esse quadro é rever a rotina dessas instâncias, abrindo espaço em sua agenda para que os conselheiros possam agir como atores polí- 
ticos, construindo pontes e articulações, de forma a ampliar o poder relativo dos conselhos nas políticas setoriais.

Os conselhos têm despendido uma energia significativa com questões relativas ao seu funcionamento interno. Os estudos demonstram que boa parte de suas agendas voltam-se para a discussão de temas relativos a sua própria dinâmica organizacional interna. A avaliação de Moraes sobre o Conselho Estadual de Direitos da Criança e do Adolescente (CEDCA) de Santa Catarina poderia ser generalizada para muitos conselhos hoje em funcionamento no Brasil:

Houve uma centralização da relação entre o Conselho e o governo do Estado, ficando para o segundo plano a busca de legitimidade na relação com a opinião pública, especialmente a socialização de informações e a formação sobre os direitos da criança e do adolescente. Com isto, persistiu a gestão tradicional e o conselho foi reduzido à sua existência formal. (Moraes, 1999, apud Tatagiba, 2002)

A bibliografia sobre os conselhos produzida nos anos 1990 já havia identificado essa tendência. $\mathrm{Na}$ análise das atas e resoluções era possível notar que o principal tema sobre o qual os conselheiros se debruçavam dizia respeito à sua própria dinâmica interna (Tatagiba, 2002). Os temas mais relacionados ao controle social, ao desenho da política pública ou as prioridades de investimento público, apesar de importantes, eram menos presentes nas pautas de discussão dos conselhos. Dentre essas discussões mais organizacionais, ganham destaque as questões relativas à elaboração dos regimentos internos e a preparação e eleição dos novos conselheiros, quando da mudança de gestão. Houve um grande investimento dos movimentos, das ONGs, das universidades e do governo no sentido de que os conselhos completassem seu processo de institucionalização com a elaboração das suas regras internas, e isso se refletiu no predomínio desses temas. No contexto dos anos 1990, isso era esperado, visto que se tratava de criar a própria estrutura participativa. O problema é que essa tendência a uma atuação voltada para dentro parece não ter sido superada nas décadas seguintes. E o mais curioso é que os estudos sobre os conselhos parecem também ter sido "contaminados" por essa tendência, elegendo objetos de pesquisa que se constroem a partir da análise das dinâmicas internas ao conselho, como os problemas na relação entre os conselheiros societários e estatais, a falta de democracia interna, a natureza das decisões tomadas no pleno do conselho etc. As questões relativas à relação do conselho com seu ambiente externo foram pouco debatidas. Ou seja, se discutiu muito o poder nos conselhos e 
pouco o poder dos conselhos, para usar os termos presentes em Silva, Côrtes et al. (2009).

Ao lado de uma agenda mais voltada ao funcionamento interno dos conselhos, os estudos também mostram que os conselhos têm investido grande parte de sua energia no desempenho de funções técnicas e burocráticas, mantendo uma agenda no varejo e atuando reativamente em resposta às demandas provenientes do Executivo, enquanto decisões importantes continuam correndo por fora, nas tramas desconexas que conformam a rede de produção da política pública. Essas atividades têm drenado parte significativa da energia dos conselheiros. Principalmente no caso dos conselhos das áreas sociais, há um grande investimento nas atividades de inscrição de entidades e aprovação de projetos voltados para o recebimento de financiamento público. ${ }^{12}$ Conselheiros da sociedade civil registram, fiscalizam entidades, avaliam projetos, fazem parecer, enviam relatórios, pedem e avaliam prestações de contas. Aprovam e rejeitam pedidos. $\mathrm{O}$ exercício dessa função, sem uma estrutura de trabalho adequada, exige um considerável trabalho extra dos conselheiros e muitas vezes mantêm os conselhos presos a um interminável ciclo que envolve aprovação e revisão dos registros concedidos, principalmente em cidades de médio e grande porte.

Se esse é um problema mais presente nos conselhos da área social, estudos mostram que ele não está restrito a esses. Como parte de uma pesquisa levada a cabo pela Rede Nacional Observatório das Metrópoles que pretende realizar um amplo diagnóstico nacional sobre o funcionamento dos conselhos das cidades, a pesquisa sobre Maringá(PR) já revelou que o assunto preponderante nessas instâncias diz respeito à análise e aprovação de RIVs — Relatório de Impacto de Vizinhança, requisito legalmente exigido para início e reforma de empreendimentos urbanos. Das cem atas pesquisadas, em setenta havia a presença desse assunto, o que permitiu concluir que a discussão de assuntos referentes ao planejamento mais amplo da política urbana na cidade ficou prejudicada por falta de tempo. ${ }^{13}$

É importante ressaltar que não estamos dizendo que ao fazerem isso os conselhos não deliberam ou não incidem sobre a política. Evidentemente, ao

12. Pesquisa realizada por Cunha (2011) junto aos CMAS mostra que esse é um problema que tende a estar mais concentrado nas capitais, e com importantes variações entre elas.

13. Esse levantamento foi realizado por Francieli Martins Batista como parte de seu projeto de iniciação científica desenvolvido na Universidade Estadual de Maringá. 
aprovar cadastros de entidades e os RIVs, tanto os conselhos de política social como os das cidades incidem efetivamente nas políticas de suas respectivas áreas. Entretanto, estamos dizendo que essa incidência no geral se restringe à fase de implementação da política — ou seja, quando as decisões relevantes já foram tomadas - e que exigem um tipo de ação dos conselhos que os mantêm presos a uma lógica burocrática e tarefeira. Essa lógica faz os conselheiros agirem mais como se fossem funcionários do governo, técnicos das secretarias do Poder Executivo que executam funções evidentemente importantes, mas não necessariamente aquelas correspondentes à definição e planejamento mais amplo das políticas.

Pesquisa realizada junto aos Conselhos de Criança e Adolescente e Assistência Social na cidade de São Paulo são bons exemplos. ${ }^{14}$ No caso do CMDCA, o que a pesquisa demonstra é que o Conselho manteve ao longo de sua história uma capacidade de definir critérios e diretrizes para o atendimento às crianças e adolescentes conferindo transparência a uma rede que atuou secularmente de forma pulverizada e particularista. Nesse sentido, a sua capacidade de incidência parece inquestionável. Afinal, construir diretrizes significa definir o que deve ser considerado adequado, o que deve ser valorizado e que, portanto, merece e pode receber financiamento público. Independente de sua efetividade prática, a norma cria e afirma um critério de valor, um parâmetro para o julgamento e a crítica. O problema é que o conselho não apenas definiu a norma, mas tomou para si o trabalho cotidiano de fiscalizar sua aplicação, o que significa incluir em sua rotina de trabalho a execução da tarefa burocrático-administrativa de aprovar programas específicos e conceder registros a entidades específicas. Nos registros presentes na Ata de 9/6/2006 temos um pequeno exemplo do que isso significa numa cidade como São Paulo. Num balanço da gestão 2004-06, a conselheira faz a conta: no CMDCA há 1.157 organizações com registro; considerando que cada organização tem três serviços, chega-se a um total aproximado de quase 4 mil programas registrados no Conselho! Como explica a conselheira, as entidades e o CMDCA estão continuamente implicados num ciclo que envolve aprovação e revisão dos registros concedidos:

Nós temos um Conselho hoje com mais ou menos 1200 registros e considerando que cada entidade desenvolve não menos do que dois, três programas, então mais ou

14. Para a apresentação detalhada dessas pesquisas, remetemos a Tatagiba e Teixeira (2007a e 2007b). 
menos quase 4 mil programas e aí uma ou duas técnicas pra avaliar esses planos, então não dá conta, não dá conta [...]. É uma questão tarefeira do Conselho, é um desgaste. (Tatagiba e Teixeira, 2007a, p. 42)

A pesquisa também mostra que apesar dos protestos dos conselheiros pelo fato de serem excluídos do planejamento da política, na prática o Conselho não se qualificou ou investiu suas fichas no desempenho desse papel,

embora seja uma instituição participativa, o CMDCA vem mostrando nos últimos anos de sua história uma vinculação muito mais forte com os governos, do que com a sociedade civil. [...]. A linguagem, a lógica e a dinâmica de ação do Conselho sugerem uma burocratização dessa instância, que talvez explique as dificuldades que o Conselho encontra para assumir um papel mais propositivo e inovador, mesmo na fase de implementação da política, que é onde se concentra sua capacidade de incidência. (Tatagiba e Teixeira, 2007a, p. 107)

O caso se repete no Conselho Municipal de Assistência. Como afirmam as autoras, ao longo de sua existência, o Comas tomou para si funções técnico-administrativas que acabaram sufocando a possibilidade de o Conselho atuar na politização de novos temas e questões, e completam. "A condição subordinada na qual se dá a inclusão dos usuários no Conselho e a falta de visibilidade e transparência do Conselho parece uma outra face dessa moeda" (Tatagiba e Teixeira, 2007b). No que se refere à fase de planejamento da política, a influência do Conselho é muito reduzida, sendo seu dever avaliar e aprovar (ou não) as propostas governamentais para a área. A partir dessas avaliações, concluem as autoras: "O Comas é uma instituição que está integrada nos circuitos de produção da política, numa posição periférica em relação aos processos que envolvem as decisões políticas relevantes para a área" (Tatagiba e Teixeira, 2007b).

Esses exemplos mostram que é imperioso "criar vazios produtivos na agenda dos conselhos", de maneira que os conselheiros possam ter tempo e energia para pensar a política de forma ampla e generosa, propor saídas, disputá-las na esfera pública, criar articulações no interior dos governos, dos Legislativos, comprometer o Judiciário etc. Criar "vazios produtivos" na agenda cotidiana dos conselhos para que os conselheiros possam se dedicar ao fortalecimento dos elos de ligação com o público fora dos conselhos, criando redes de solidariedade e mobilização social em torno de temas específicos. 
Ao longo deste texto argumentamos que o cumprimento das apostas que definem o sentido político democratizante dos conselhos depende do fortalecimento da sua face pública, expressa no adensamento e vitalização dos seus vínculos com a sociedade civil e o Estado. Isto significa apostar energias nas mediações necessárias entre conselho, sociedade civil e cidadãos. Implica também disposição para incidir no ambiente institucional mais amplo nos quais os conselhos estão inseridos, buscando o seu reconhecimento como instância legítima na qual as normativas do Estado podem ser interpeladas segundo as exigências da justiça e dos direitos.

Para isso, é necessário rever as funções hoje atribuídas aos conselhos. Não é possível fazer tudo ao mesmo tempo. Os recursos são escassos, os conselheiros não são funcionários públicos, a infraestrutura dos conselhos no geral não lhes permite contar com uma assessoria jurídico-administrativa necessária para a complexidade que tratam. Face ao acúmulo de funções, os conselheiros acabam abrindo mão de suas funções propriamente políticas de proposição de temas, de explicitação de conflitos, de construção de acordos e articulações, voltando-se penosamente para atividades que os distanciam da sociedade civil e os circunscrevem a uma atuação estatal e institucional meramente burocrática. Essas funções que o conselho chamou para si ampliam o custo da participação para a sociedade civil e conspiram contra o fortalecimento dessas instâncias junto à sociedade e ao Estado. Por isso, defendemos enfaticamente a necessidade de rever as rotinas dos conselhos como condição de explorar a sua condição de instituições híbridas que exercitam a política, desafiando o instituído em nome dos direitos e da justiça.

\section{Recebido em 3/10/2011 - Aprovado em 28/11/2011}

\section{Referências bibliográficas}

ABRANCHES, M.; AZEVEDO, S. A capacidade dos conselhos setoriais em influenciar políticas públicas: realidade ou mito? In: SANTOS JÚNIOR, O.; AZEVEDO, S.; RIBEIRO, L. C. Q. (Orgs.). Governança democrática e poder local: a experiência dos conselhos municipais no Brasil. Rio de Janeiro: Revan, Fase, 2004. 
ALMEIDA, C. C. R. Conselhos gestores e regulação: a assistência social em tempos de transição. Política \& Sociedade, Florianópolis, v. 8, n. 15, p. 251-269, 2009.

AVRITZER, L. Sociedade civil, instituições participativas e representação: da autorização à legitimação da ação. Dados, revista de Ciências Sociais, Rio de Janeiro, v. 50, n. 3, p. 443-464, 2007.

Experiências nacionais de participação social. São Paulo: Cortez, 2009.

; PEREIRA, M. de Lourdes Dolabela. Democracia, Participação e Instituição Híbridas. In: Teoria e Sociedade. Belo Horizonte: UFMG. n. especial, mar. 2005.

CÔRTES, S. V.(Org.). Participação e saúde no Brasil. Rio de Janeiro: Fiocruz, 2009.

et al. Conselho Nacional de Saúde: histórico, papel institucional e atores estatais e societais. In: CÔRTES, S. V. (Org.). Participação e saúde no Brasil. Rio de Janeiro: Fiocruz 2009.

CUNHA, E. S. M. Metamorfose da representação política: lições práticas dos conselhos municipais de Saúde no Brasil. In: AVRITZER, L. A dinâmica da participação local no Brasil. São Paulo: Cortez, 2011.

DAGNINO, E. (Org.). Sociedade civil e espaços públicos no Brasil. Rio de Janeiro: Paz e Terra, 2002.

; OLVERA, A.; PANFICHI, A. (Orgs). A disputa pela construção democrática na América Latina. Rio de Janeiro: Paz e Terra: Campinas: Ed. Unicamp, 2006.

DOWBOR, M.; HOUTZAGER, P.; SERAFIM, L. Enfrentando os desafios da participação em espaço participativos. São Paulo: Cebrap: IDS, 2008.

FELTRAN, G. de S. Desvelar a política na periferia: histórias de movimentos sociais em São Paulo. São Paulo: Associação Editorial Humanitas: Fapesp, 2005.

GURZA LAVALLE, A.; ISUNZA VERA, E. Precisiones conceptuales para el debate contemporáneo sobre la innovación democrática: participación, controles sociales y representación. In: (Orgs.). La innovación democrática en América Latina: tramas y nudos de la representación, la participación y el control social. México: Centro de Investigaciones y Estudios Superiores en Antropología Social, Universidad Veracruzana, 2010.

GURZA LAVAllE, A., HOUTZAGER, P. P.; CASTELlO, G. Democracia, pluralização da representação e sociedade civil. Lua Nova, São Paulo, v. 67, n. 67, p. 49-103, 2006.

HABERMAS, J. Direito e democracia: entre facticidade e validade. Rio de Janeiro: Tempo Brasileiro, 1997.

Mudança estrutural da esfera pública. Rio de Janeiro: Tempo Brasileiro, 1984.

LÜCHMANN, L. H. A representação no interior das experiências de participação. Lua Nova, São Paulo, n.70, p. 139-170, 2007. 
MACPHERSON, C. B. A. Democracia liberal: origens e evolução. Rio de Janeiro: Jorge Zahar, 1978.

MATEOS, S. B. A construção da democracia participativa. Desafios do Desenvolvimento, Brasília, ano 8, n. 65, p. 18-33, 2011.

MINISTÉRIO DO DESENVOLVIMENTO SOCIAL E COMBATE À FOME. Norma Operacional Básica do SUAS — NOB/SUAS. Brasília, 2005.

. Politica Nacional de Assistência Social. Brasília, 2004.

MORONI, José Antonio. Entrevista concedida à Abong (Associação Brasileira de ONGs), no dia 11/7/2011, disponível em: <http:/www.reformapolitica.org.br/entrevistas/170-ha-o-desafio-de-se-pensar-em-sistema-de-participacao-popular-que-abarque-todas-as-formas-organizativas-da-sociedade-afirma-moroni.pdf>. Acesso em: 9 set. 2011.

PATEMAN, Carole. Participação e teoria democrática. Rio de Janeiro: Paz e Terra, 1992.

PEREIRA, M. L. D. As políticas públicas locais e os processos de hibridização no Brasil e na América Latina. In: DAGNINO, E.; TATAGIBA, L. Democracia, sociedade civil e participação. Chapecó: Argus, 2007

PERUZZOTTI, H.; SELEE, A. Participatory Innovation and Representative Democracy in Latin America. In. SELEE, A.; PERUZZOTTI, H. (Eds.). Participatory innovation and representative democracy in Latin America. Washington: Woodrow Wilson Center Press, 2009.

SANTOS JÚNIOR, O.; AZEVEDO, S.; RIBEIRO, L. C. Q. Democracia e gestão local: a experiência dos conselhos municipais no Brasil. In: (Orgs.). Governança democrática e poder local: a experiência dos conselhos municipais no Brasil. Rio de Janeiro: Revan, Fase, 2004.

TATAGIBA, L. Os conselhos gestores e a democratização das políticas públicas no Brasil. In: DAGNINO, E. (Org.). Sociedade civil e espaços públicos no Brasil. São Paulo: Paz e Terra, 2002.

. A institucionalização da participação: os conselhos municipais de políticas públicas na cidade de São Paulo. In: AVRITZER, L. (Org.). A participação em São Paulo. São Paulo: Unesp, 2004.

. A questão dos atores, seus repertórios de ação e implicações para o processo participativo. In: PIRES, R. R. C. (Org.). Efetividade das instituições participativas no Brasil: estratégias de avaliação. Brasília: Ipea, v. 7, p. 171-186, 2011.

; TEIXEIRA, A. C. C. O papel do CMDCA na política de criança e adolescente em São Paulo. São Paulo: Pólis/PUC-SP, 2007a. (Cadernos do Observatório, v. 28.)

. O papel do Comas na política de assistência social em São Paulo. São Paulo: Pólis/PUC-SP, 2007b. (Cadernos do Observatório, 30.) 
TÓTORA, S.; CHAIA, V. Conselhos municipais e a institucionalização da participação política: a região metropolitana de São Paulo. In: SANTOS JÚNIOR, O.; AZEVEDO, S.; RIBEIRO, L. C. Q. (Orgs.). Governança democrática e poder local: a experiência dos conselhos municipais no Brasil. Rio de Janeiro: Revan, Fase, 2004.

URBINATI, N. Representative democracy: principles \& genealogia. Chicago: University of Chicago Press, 2006.

VIDAL, L. de F. A prática conselhista e a representação política: um estudo de caso sobre o Conselho Municipal dos Direitos da Criança e do Adolescente, Maringá. 2011. Dissertação (Mestrado) — Programa de Pós-Graduação em Ciências Sociais, Universidade Estadual de Maringá, Maringá, 2011.

YOUNG, I. M. Representação política, identidade e minorias. Lua Nova, São Paulo, n. 67, p. 139-190, 2006.

. Inclusion and democracy. Oxford: University Press, 2000. 